\title{
Retraction Note: Determination of acetaminophen spatial distribution and content in tablets using confocal micro- Raman spectroscopy mapping
}

\author{
Hong-yu Jiang • Chang-hong Ding • Yue Wang • \\ Ying-xin Zhang • Ahmed Mohammed · Yan Pan • \\ Bing Han
}

Published online: 10 August 2021

(C) Springer Nature B.V. 2021

\section{Retraction Note to: J Nanopart Res (2020) 22:265 \\ https://doi.org/10.1007/s11051-020-04970-z}

The Editor-in-Chief and the Publisher have retracted this article. The article was accepted as part of a guest-edited special issue in Journal of Nanoparticle Research. Before the special issue was finalized, the Editor-in-Chief detected problems with editorial handling and peer review and decided not to proceed with the special issue [1].

Post publication peer review found that this article is out of scope for the journal, which focuses on original contributions on nanoscale phenomena and processes, and does not meet the standards required by the journal.
None of the authors agree to this retraction

\section{References}

1. Pinna N, Clavel G, Roco MC (2020) The journal of nanoparticle research victim of an organized rogue editor network! J Nanopart Res 22:376. https://doi.org/10.1007/ s11051-020-05094-0

Publisher's note Springer Nature remains neutral with regard to jurisdictional claims in published maps and institutional affiliations.

The original article can be found online at https://doi.org/ 10.1007/s11051-020-04970-z.

H. Jiang · Y. Wang · Y. Zhang · A. Mohammed ·

B. Han $(\triangle)$

Department of Biopharmacy, School of Pharmacy, Jilin

University, Changchun 130021, China

e-mail: hanbingyxy@hotmail.com

C. Ding

Aviation University Air Force, Changchun 130012, China

Y. Pan

Department of Pharmaceutics, Jilin Provincial People's

Hospital, Changchun 130021, China 